\title{
Isolated and Recurrent Peripheral Facial Palsy Revealing Primary Sjogren's Syndrome
}

\author{
Salem Bouomrani ${ }^{1,2 *}$, Mouna Guermazi ${ }^{1,2}$, Souad Yahyaoui ${ }^{1}$, Nesrine Regaïeg ${ }^{1,2}$ and Hassène Baïli $^{1}$ \\ ${ }^{1}$ Department of Internal medicine. Military Hospital of Gabes, Gabes 6000, Tunisia
}

${ }^{2}$ Sfax Faculty of Medicine, University of Sfax, Sfax 3029, Tunisia

*Corresponding author: Salem Bouomrani, Department of Internal medicine, Gabes 6000, Tunisia

\begin{abstract}
Peripheral facial palsy (PFP) is often idiopathic; a secondary systemic cause is noted in less than $1.2 \%$ of cases. Primary Sjogren's Syndrome (PSS) remains an exceptional and often insufficiently known etiology of facial paralysis, and only a few sporadic cases are reported in the medical literature. These inaugural forms of the disease represent a real diagnostic challenge for clinicians. We report an original observation of isolated and recurrent PFP as inaugural symptom of PSS in a 53-year-old female with no notable pathological history.
\end{abstract}

Keywords: Peripheral facial palsy; Primary Sjögren’s syndrome; Facial paralysis; Neuro Sjogren

\section{Introduction}

Primary Sjögren's syndrome (PSS) is an autoimmune disease characterized by focal lymphoid infiltration of the exocrine glands, mainly manifested by dry ocular and oral syndrome [1]. During the course of the disease, one-third of the patients develop extraglandular lesions: pulmonary, neurological, renal, hepatic and cardiac, which signal the systemic nature of this disease and condition its prognosis $[2,3]$. The prevalence of this connective tissue disease is estimated at $1-3 \%$ of the general population $[1,4]$ and can reach as much as $4.8 \%$ in Europe [2]. The neurological manifestations of this disease are observed in $15-20 \%$ of cases and are highly polymorphic and far dominated by peripheral neuropathy [5-8].

The spectrum of PSS-associated neurological manifestations may include: multiple mononeuropathy, symmetrical axonal sensorimotor polyneuropathy, sensory ataxic neuropathy, painful sensory neuropathy, cranial neuropathy, autonomic neuropathy, radiculoneuropathy, aseptic meningitis, encephalopathy, psychiatric symptoms, chorea, seizures, chronic myelopathies, multiple sclerosis-like syndrome, and cognitive impairment [5-8]. Neurological involvement may be the first manifestation of PSS in approximately $25 \%$ of cases [7]. Of all the possible neurological manifestations of PSS, peripheral facial palsy (PFP) remains exceptional and unusual [9], and only a few sporadic cases were reported in the medical literature [9-12]; these inaugural forms of the disease represent a real diagnostic challenge for clinicians. We report an original observation of isolated and recurrent PFP as inaugural symptom of PSS.

\section{Case Report}

A 53-year-old Tunisian patient, with no notable pathological history, was referred to our department for recurrent PFP. She was treated by her family doctor for three episodes of PFP occurring within a year and a half without any other associated abnormalities. This PFP was right in two times and left in one time. The etiological investigations requested by his treating physician, including a specialized ENT examination and a cerebral CT-scan, were without abnormalities. The diagnosis of idiopathic PFP (Bell's palsy) was retained. The patient was treated with short course corticosteroid and vitamin therapy but without improvement.

In somatic examination, the patient was apyretic, with correct conscious, respiratory, and hemodynamic status. We noted a marked dryness of the skin and the tongue. 
Laboratory tests revealed a marked biological inflammatory syndrome with erythrocyte sedimentation rate at $68 \mathrm{~mm} / \mathrm{H} 1$, C-reactive protein at $18 \mathrm{mg} / \mathrm{l}$, and polyclonal hypergammaglobulinemia at $24.6 \mathrm{mmol} / \mathrm{l}$. the other basic tests were within normal limits: blood count, creatinine, serum calcium, ionogram, fasting glucose, transaminases, muscle enzymes, lipid parameters, and thyroid hormones. Immunological exploration showed positive anti-nuclear autoantibodies at $1 / 640$ with positive anti-SSA antibodies at 50 IU. The specialized ophthalmologic examination objectified xerophthalmia with bilateral filamentous keratitis and a positive Schirmer's test.

Biopsy of the accessory salivary glands showed a stage 3 chronic sialadenitis according to the Chisholm classification. Thus, the diagnosis of PSS was retained based on the following criteria: xerophthalmia, xerostomia, positive ophthalmological tests, stage 3 chronic sialadenitis, and positive anti-nuclear and anti-SSA antibodies. Cerebrospinal fluid analysis and cerebromedullary MRI did not show signs suggestive of specific neurological involvement of PSS (neuro-Sjögren). Similarly, other systemic complications of PSS and a possible lymphomatous transformation were eliminated by specific investigations. At the end of this assessment, the diagnosis of a recurrent and isolated PFP revealing PSS was retained. The patient was treated with systemic corticosteroid therapy at a dose of $1 \mathrm{mg} / \mathrm{kg} /$ day and hydroxychloroquine at a dose of $400 \mathrm{mg} / \mathrm{d}$, salicylic acid at a dose of $100 \mathrm{mg} / \mathrm{d}$, and symptomatic treatment of xerophthalmia and xerostomia, with favorable evolution. No recurrence of the PFP has been noted for five years now.

\section{Discussion}

PFP is often idiopathic (Bell's palsy or FRP); a secondary systemic cause is noted in less than $1.2 \%$ of cases [13]. PSS remains an exceptional [11] and often insufficiently known etiology of facial paralysis [11,14]. Indeed, only a few sporadic cases have been reported in the literature [9-12,15]. In large series of PSS, this neurological manifestation remains unusual: in fact, only two cases of PFP associated with PSS were found in the series of Teixieira F et al of 93 patients followed for PSS [14], no case has was noted in the European series of 392 patients with PSS of whom 74 had neuro-Sjögren's [8], and no case of PFP was reported in the Ye W et al series of 566 patients with PSS of whom 184 had neurological signs [6]. PSS-associated PFP can be uni- or bi-lateral [12], episodic or most often recurrent [11], isolated or more often integrated in the framework of a complex neurological attack [11] and can remain for a long time the only manifestation of the disease $[11,15]$. PFP associated with PSS usually responds well to systemic corticosteroids and others specific therapies for this autoimmune disease.

These forms of isolated and SSP-revealing cranial neuropathies are often ignored and neglected by clinicians, and thus sometimes responsible for a very important diagnosis delay [16]. The exact pathophysiology of this neuropathy is not very well known. It appears to be multifactorial involving vasculitis, autoimmunity, inflammation, and cryoglobulinemia [4,5]. A reported case of PSSassociated PFP involved, in addition to these classic pathogenic factors, a vitamin B12 deficiency [11]. Finally, it should be kept in mind that a PFP for rapid onset and/or progression during PSS should raise concerns about the lymphomatous transformation of this disease [17].

\section{Conclusion}

Peripheral facial palsy is an exceptional and uncommon neurologic complication of PSS. The isolated and inaugural forms are often ignored by health practitioners and represent a real diagnostic challenge. It is thus necessary to evoke the diagnosis of PSS in front of any PFP that does not proven, particularly if recurrent and in elderly. Early diagnosis and adequate management can improve the prognosis of this disease, especially that a lymphomatous transformation can be announced by a PFP arising and/or progressing rapidly.

\section{References}

1. Peri Y, Agmon Levin N, Theodor E, Shoenfeld Y (2012) Sjogren's Syndrome, the old and the new. Best Pract Res Clin Rheumatol 26(1): 105-117.

2. Both T, Dalm VA, van Hagen PM, van Daele PL (2017) Reviewing primary Sjögren's syndrome: beyond the dryness - From pathophysiology to diagnosis and treatment. Int J Med Sci 14(3): 191-200.

3. Marshall LL, Stevens GA (2018) Management of Primary Sjögren's Syndrome. Consult Pharm 33(12): 691-701.

4. Morreale M, Marchione P, Giacomini P, Pontecorvo S, Marianetti M, et al. (2014) Neurological involvement in primary Sjögren syndrome: a focus on central nervous system. PLoS One 9(1): e84605.

5. Koike H, Sobue G (2013) Sjogren's syndrome-associated neuropathy. Brain Nerve 65(11): 1333-1342.

6. Ye W, Chen S, Huang X, Qin W, Zhang T, et al. (2018) Clinical features and risk factors of neurological involvement in Sjögren's syndrome. BMC Neurosci 19(1): 26.

7. Fauchais AL, Magy L, Vidal E (2012) Central and peripheral neurological complications of primary Sjögren's syndrome. Presse Med 41(9 Pt 2): e485-93.

8. Carvajal Alegria G, Guellec D, Mariette X, Gottenberg JE, Dernis E, et al. (2016) Epidemiology of neurological manifestations in Sjögren's syndrome: data from the French ASSESS Cohort. RMD Open 2(1): e000179.

9. Hadithi M, Stam F, Donker AJ, Dijkmans BA (2001) Sjögren's syndrome: an unusual cause of Bell's palsy. Ann Rheum Dis 60(7): 724-725.

10. Berault Dupont C, Saveuse H, Dechy H, Lesur G, Rouveix E, et al. (1992) Peripheral facial paralysis in primary Gougerot-Sjögren syndrome. Presse Med 21(2): 83-84.

11. Rousso E, Noel E, Brogard JM, Blicklé JF, Andrès E (2005) Recurrent facial palsy, primary Gougerot-Sjögren's syndrome and vitamin B12 deficiency. Presse Med 34(2 Pt 1): 107-108.

12. Uchihara T, Yoshida S, Tsukagoshi H (1989) Bilateral facial paresis with Sjögren's syndrome. J Neurol 236(3): 186.

13. Peitersen E (2002) Bell's palsy: The spontaneous course of 2500 peripheral facial nerve palsies of different etiologies. Acta Otolaryngol (549): 4-30. 
14. Teixeira F, Moreira I, Silva AM, Vasconcelos C, Farinha F, et al. (2013) Neurological involvement in Primary Sjögren Syndrome. Acta Reumatol Port 38(1): 29-36.

15. Rafai MA, Boulaajaj FZ, Moutawakil F, Addali N, El Moutawakkil B, et al. (2009) Neurological manifestations revealing primitive GougerotSjogren syndrome: 9 cases. Joint Bone Spine 76(2): 139-145.

16. Colaci M, Cassone G, Manfredi A, Sebastiani M, Giuggioli D, et al. (2014) Neurologic Complications Associated with Sjögren's Disease: Case
Reports and Modern Pathogenic Dilemma. Case Rep Neurol Med 2014: 590292 .

17. Gorodetskiy VR, Klapper W, Probatova NA, Vasilyev VI, Rozhnova EV (2018) Simultaneous Occurrence of Rosai-Dorfman Disease and Nodal Marginal Zone Lymphoma in a Patient with Sjögren's Syndrome. Case Rep Hematol 2018: 7930823.

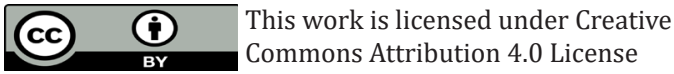

To Submit Your Article Click Here: Submit Article

DOI: $10.32474 / 0 J N B D .2019 .02 .000137$

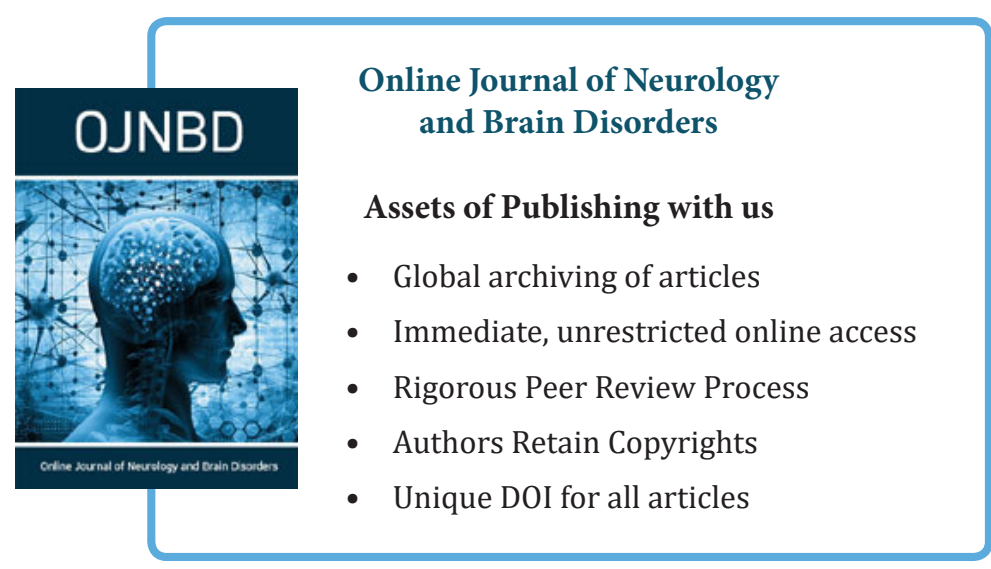

